\title{
Anti-Inflammatory and Gastroprotective Evaluation of Prodrugs of Piroxicam
}

\author{
Vivekkumar K. Redasani, Amol B. Shinde, and Sanjay J. Surana \\ R. C. Patel Institute of Pharmaceutical Education and Research, Shirpur 425 405, India \\ Correspondence should be addressed to Vivekkumar K. Redasani; vivek.redasani@gmail.com
}

Received 28 June 2014; Accepted 13 August 2014; Published 26 August 2014

Academic Editor: Gyula Mozsik

Copyright ( 2014 Vivekkumar K. Redasani et al. This is an open access article distributed under the Creative Commons Attribution License, which permits unrestricted use, distribution, and reproduction in any medium, provided the original work is properly cited.

\begin{abstract}
Therapeutically potential prodrugs of piroxicam were synthesized by effective masking of enolic hydroxyl group through generation of ester congeners. The reaction facilitated using N, $\mathrm{N}^{\prime}$-dicyclohexylcarbodiimide coupled with acetic acid, benzoic acid, $\mathrm{p}$-toluic acid, m-toluic acid, and cinnamic acid. Synthesized prodrugs were characterized for confirmation of the said structures. The modification of piroxicam showed better anti-inflammatory activity as evoked by all prodrugs. Interestingly, compound $\mathbf{3 e}$, cinnamic acid ester prodrug, depicted 75 percent inhibition of rat paw edema as compared to 56 percent for parent piroxicam at $6 \mathrm{~h}$ of study. The present work proves the applicability not only with increased anti-inflammatory activity, but also with marked attenuation in ulcerogenicity. Novel prodrug $\mathbf{3 e}$, cinnamic acid derivative, was found to be the least ulcerogenic having ulcer index of 0.67 as compared to parent drug piroxicam with 2.67 .
\end{abstract}

\section{Introduction}

The gastrointestinal side effects such as dyspepsia and frank ulceration constitute the most frequent of every adverse reaction that are caused by nonsteroidal anti-inflammatory drugs (NSAIDs) [1]. Piroxicam, 1,2-benzothiazine-3-carboxamide4-hydroxy-2-methyl- $N$-(2-pyridyl)-1,1-dioxide, is effectively employed to treat rheumatoid arthritis, osteoarthritis, and musculoskeletal inflammation [2]. It is susceptible to produce gastric ulcerations associated with gastrointestinal (GI) bleeding and hemorrhages as prominent side effects [3]. The highest flying factor in the development of GI ulceration induced by NSAIDs is the inhibition of prostaglandin synthesis, as endogenous prostaglandins are known to have cytoprotective action on gastric mucosa [4]. NSAIDs generate GI lesions by two different mechanisms: direct contact effect and generalized systemic effect which may occur after absorption following intravenous dosing [5].

Literature survey reveals modification of enolic hydroxyl group present in piroxicam resulting into prodrugs. These prodrugs showed retention of anti-inflammatory activity and reduction in GI side effects as well $[6,7]$. In an attempt to synthesize novel prodrugs of piroxicam 3(ae), in the present study we have utilized acid promoieties of pharmacophoric importance for anti-inflammatory and analgesic effect [8-10]. These prodrug derivatives were synthesized by reacting piroxicam with acids, namely, acetic acid, benzoic acid, $\mathrm{p}$-toluic acid, $\mathrm{m}$-toluic acid, and cinnamic acid in presence of $\mathrm{N}, \mathrm{N}^{\prime}$-dicyclohexylcarbodiimide (DCC) and dichloromethane (DCM) followed by characterization with physicochemical and spectral analysis. Furthermore, the pharmacological screening was carried out to evaluate preliminary biodisposition simulation for assessment of comparative effectiveness.

\section{Materials and Methods}

2.1. Materials. Piroxicam was obtained as gift samples from Cadila Healthcare Limited, Ahmadabad (India). All solvents were of analytical grade and distilled before use. Melting points were recorded on ThermoCal melting point apparatus (Analab Scientific Instruments Pvt., Ltd.) and are uncorrected. Infrared (FTIR) spectra were recorded using $\mathrm{KBr}$ on FTIR-8400S Shimadzu. ${ }^{1}$ HNMR spectra were recorded on Joel-FT-NMR-300 MHz using $\mathrm{CDCl}_{3}$ as solvent and tetramethylsilane (TMS) as internal standard. Chemical shifts $(\delta)$ are expressed in $\delta$ ppm and coupling constants $(J)$ were 


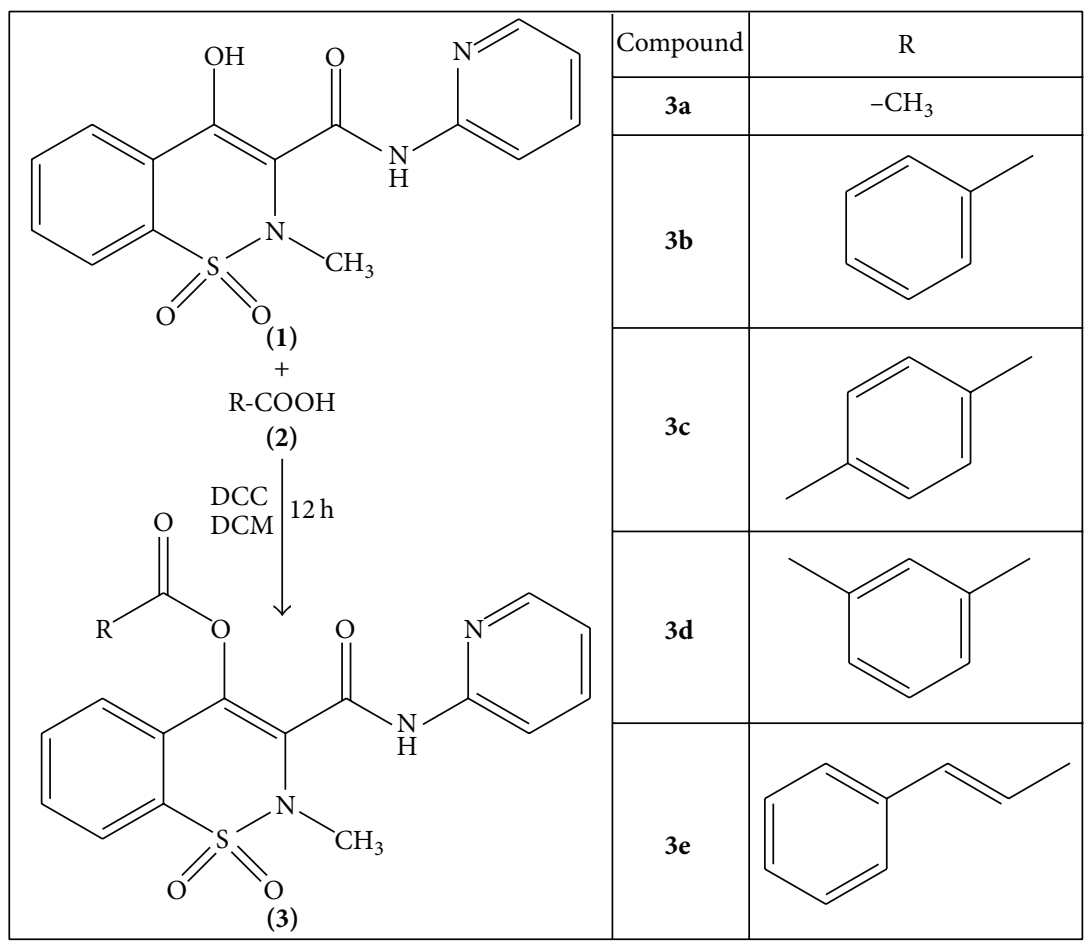

SCHeme 1: Synthesis of piroxicam prodrugs 3(a-e) DCC-N,N,-dicyclohexylcarbodiimide, DCM-dichloromethane.

measured in Hz. Mass spectra were recorded on Hewlett Packard G180017 GCD system.

Animal experiments were conducted on adult Wistar rats of either sex weighing between 150 and $200 \mathrm{mg}$. Animals were procured from animal house of the institute. Animals of either sex were divided into groups of six animals each $(n=6)$ for anti-inflammatory and gastroprotective activity. The paw edema volume was measured with the help of Ugo Basile Plethysmometer (7140). Results are expressed as mean \pm SEM. Statistical evaluation was performed using analysis of variance followed by Dunnett's test for subgroup comparison.

2.2. Synthesis of Title Compounds (3a-3e). The targeted prodrugs of piroxicam were synthesized as in Scheme 1. Individual acids $(6.75 \mathrm{mM})$ were dissolved in $15 \mathrm{~mL}$ of dichloromethane (DCM) in RBF fitted with a condenser and drying tube at its upper end in order to maintain anhydrous conditions. The acid solution was cooled to $0^{\circ} \mathrm{C}$. In another beaker (DCC) $(6.75 \mathrm{mM})$ was dissolved in DCM. The DCC solution and parent drug piroxicam $(6.75 \mathrm{mM})$ were added to acid solution at $0^{\circ} \mathrm{C}$. The reaction mixture was stirred at $0^{\circ} \mathrm{C}$ for an hour. The ice bath was removed and reaction mixture was stirred at room temperature for the next $12 \mathrm{~h}$ with a condenser attached with drying tube. It was then filtered to separate $\mathrm{N}, \mathrm{N}^{\prime}$-dicyclohexyl urea. The filtrate was washed twice with $25 \mathrm{~mL}$ of $5 \%$ sodium bicarbonate solution to remove excess/unreacted acid. The aqueous layer was separated and organic layer was then washed twice with sodium hydroxide, in order to remove excess/unreacted drug. The organic layer was dried and solvent was distilled out under reduced pressure in order to avoid thermal degradation of ester prodrugs. The oily residue obtained after distillation was then recrystallized by dissolving it in sufficient quantities of $n$-hexane [11].

2.2.1. 2-Methyl-1,1-dioxide-3-(pyridine-2-yl carbomoyl)-2Hbenzo[e] [1,2] thiazin-4-yl-acetate ( $3 \boldsymbol{a})$. Yield: $68 \%$, mp $125-$ $127^{\circ} \mathrm{C}, \mathrm{UV}\left(\mathrm{CHCl}_{3}\right): \lambda_{\max } 317 \mathrm{~nm}, \mathrm{IR}(\mathrm{KBr}) \mathrm{cm}^{-1}: 3333(-\mathrm{NH})$, $1778(-\mathrm{C}=\mathrm{O}), 1683(-\mathrm{C}=\mathrm{O}),{ }^{1} \mathrm{HNMR}\left(300 \mathrm{MHz}, \mathrm{CDCl}_{3}\right)$ $\delta / \mathrm{ppm}: 2.44\left(3 \mathrm{H}, \mathrm{s},-\mathrm{CH}_{3}\right), 2.92\left(3 \mathrm{H}, \mathrm{s},-\mathrm{CH}_{3}\right), 7.10(4 \mathrm{H}, \mathrm{m}$, pyridino), $7.60-8.10(4 \mathrm{H}, \mathrm{m}, \mathrm{Ar}-\mathrm{H}), 9.09(1 \mathrm{H}, \mathrm{s},-\mathrm{NH})$; MS $(70 \mathrm{eV}) \mathrm{m} / \mathrm{z} 374$.

2.2.2. 2-Methyl-1,1-dioxide-3-(pyridine-2-yl carbomoyl)- $2 \mathrm{H}$ benzo[e] [1,2] thiazin-4-yl-benzoate (3b). Yield: 65\%, mp 180$182^{\circ} \mathrm{C}$, UV $\left(\mathrm{CHCl}_{3}\right): \lambda_{\max } 326 \mathrm{~nm}$, IR $(\mathrm{KBr}) \mathrm{cm}^{-1}: 3328(-$ $\mathrm{NH}), 1745(-\mathrm{C}=\mathrm{O}), 1681(-\mathrm{C}=\mathrm{O}),{ }^{1} \mathrm{HNMR}\left(300 \mathrm{MHz}, \mathrm{CDCl}_{3}\right)$ $\delta / \mathrm{ppm}: 3.14\left(3 \mathrm{H}, \mathrm{s},-\mathrm{CH}_{3}\right), 7.16(4 \mathrm{H}, \mathrm{m}$, pyridino), $7.26-8.32$ (13H, m, Ar-H), $9.12(1 \mathrm{H}, \mathrm{s},-\mathrm{NH}) ; \mathrm{MS}(70 \mathrm{eV}) \mathrm{m} / \mathrm{z} 436$.

2.2.3. 2-Methyl-1,1-dioxide-3-(pyridine-2-yl carbomoyl)-2Hbenzo[e] [1,2] thiazin-4-yl-3-methyl benzoate (3c). Yield: 72\%, mp $143-145^{\circ} \mathrm{C}$, UV $\left(\mathrm{CHCl}_{3}\right): \lambda_{\max } 329 \mathrm{~nm}$, IR $(\mathrm{KBr}) \mathrm{cm}^{-1}$ : $3329(-\mathrm{NH}), 1745(-\mathrm{C}=\mathrm{O}), 1685(-\mathrm{C}=\mathrm{O}),{ }^{1} \operatorname{HNMR}(300 \mathrm{MHz}$, $\left.\mathrm{CDCl}_{3}\right) \delta /$ ppm: $2.65\left(3 \mathrm{H}, \mathrm{s},-\mathrm{CH}_{3}\right), 3.19\left(3 \mathrm{H}, \mathrm{s},-\mathrm{CH}_{3}\right), 7.18$ (4H, m, pyridino), 7.40-8.26 (8H, m, $-\mathrm{ArH}), 9.05(1 \mathrm{H}, \mathrm{s},-$ $\mathrm{NH}), \mathrm{MS}(70 \mathrm{eV}) \mathrm{m} / \mathrm{z} 450$.

2.2.4. 2-Methyl-1,1-dioxide-3-(pyridine-2-yl carbomoyl)-2Hbenzo[e] [1,2] thiazin-4-yl-4-methyl benzoate (3d). Yield: 76\%, mp $156-158^{\circ} \mathrm{C}$, UV $\left(\mathrm{CHCl}_{3}\right): \lambda_{\max } 329 \mathrm{~nm}$, IR $(\mathrm{KBr}) \mathrm{cm}^{-1}$ : 
TABle 1: Pharmacological screening of piroxicam and ester prodrugs $3(\mathbf{a}-\mathbf{e})$.

\begin{tabular}{|c|c|c|c|c|c|c|c|}
\hline \multirow{2}{*}{ Compound } & \multicolumn{6}{|c|}{ Anti-inflammatory activity (\% inhibition) } & \multirow{2}{*}{ Ulcer index* } \\
\hline & $1 \mathrm{~h}$ & $2 \mathrm{~h}$ & $3 \mathrm{~h}$ & $4 \mathrm{~h}$ & $5 \mathrm{~h}$ & $6 \mathrm{~h}$ & \\
\hline Piroxicam & $12.76 \pm 0.96$ & $24.60 \pm 1.50$ & $37.87 \pm 2.0^{*}$ & $44.97 \pm 3.0$ & $50.46 \pm 2.80$ & $56.53 \pm 3.0^{*}$ & $2.67 \pm 0.51$ \\
\hline $3 a$ & $16.65 \pm 3.1$ & $28.80 \pm 1.4$ & $43.93 \pm 2.7^{*}$ & $55.77 \pm 4.9$ & $55.44 \pm 1.6$ & $60.44 \pm 4.1^{*}$ & $1.08 \pm 0.73$ \\
\hline $3 \mathbf{b}$ & $19.42 \pm 1.1$ & $33.62 \pm 2.6$ & $48.58 \pm 3.3^{*}$ & $65.11 \pm 3.7$ & $61.82 \pm 1.2$ & $65.79 \pm 4.2^{*}$ & $1.16 \pm 0.60$ \\
\hline $3 c$ & $27.33 \pm 1.4$ & $43.07 \pm 1.3$ & $55.68 \pm 1.7^{*}$ & $72.32 \pm 1.6$ & $71.78 \pm 2.2$ & $75.10 \pm 2.4^{*}$ & $0.83 \pm 0.25$ \\
\hline $3 d$ & $23.22 \pm 1.6$ & $38.52 \pm 3.3$ & $52.51 \pm 1.5^{*}$ & $72.58 \pm 4.6$ & $66.55 \pm 2.3$ & $71.14 \pm 4.1^{*}$ & $0.91 \pm 0.20$ \\
\hline $3 e$ & $27.38 \pm 3.8$ & $38.76 \pm 3.4$ & $57.33 \pm 2.6^{*}$ & $70.20 \pm 0.8$ & $75.74 \pm 1.3$ & $76.06 \pm 0.6^{*}$ & $0.67 \pm 0.25$ \\
\hline
\end{tabular}

Data represented as mean $\pm \operatorname{SEM}, n=6$.

* Statistical analysis was performed with ANOVA followed by Dunnett test $P<0.01$ with respect to control.

$3309(-\mathrm{NH}), 1776(-\mathrm{C}=\mathrm{O}), 1651(-\mathrm{C}=\mathrm{O}),{ }^{1} \mathrm{HNMR}(300 \mathrm{MHz}$, $\left.\mathrm{CDCl}_{3}\right) \delta /$ ppm: $2.56\left(3 \mathrm{H}, \mathrm{s},-\mathrm{CH}_{3}\right), 3.14\left(3 \mathrm{H}, \mathrm{s},-\mathrm{CH}_{3}\right), 7.11$ $(4 \mathrm{H}, \mathrm{m}$, pyridino $), 7.35-8.19(8 \mathrm{H}, \mathrm{m},-\mathrm{ArH}), 9.08(1 \mathrm{H}, \mathrm{s},-$ $\mathrm{NH}), \mathrm{MS}(70 \mathrm{eV}) \mathrm{m} / \mathrm{z} 450$.

2.2.5. 2-Methyl-1,1-dioxide-3-(pyridine-2-yl carbomoyl)-2Hbenzo[e] [1,2] thiazin-4-yl cinnamate (3e). Yield: $81 \%, \mathrm{mp}$ $163-165^{\circ} \mathrm{C}$, UV $\left(\mathrm{CHCl}_{3}\right): \lambda_{\max } 327 \mathrm{~nm}$, IR $(\mathrm{KBr}) \mathrm{cm}^{-1}: 3338$ $(-\mathrm{NH}), 1768(-\mathrm{C}=\mathrm{O}), 1629(-\mathrm{C}=\mathrm{O}),{ }^{1} \mathrm{HNMR}(300 \mathrm{MHz}$, $\left.\mathrm{CDCl}_{3}\right) \delta / \mathrm{ppm}: 3.15\left(3 \mathrm{H}, \mathrm{s},-\mathrm{CH}_{3}\right), 6.52(2 \mathrm{H}, \mathrm{d},-\mathrm{CH}=\mathrm{CH}-)$, $7.13(4 \mathrm{H}, \mathrm{m}$, pyridino), $7.22-8.43(9 \mathrm{H}, \mathrm{m}, \mathrm{Ar}-\mathrm{H}), 9.13(1 \mathrm{H}, \mathrm{s}$, $-\mathrm{NH}), \mathrm{MS}(70 \mathrm{eV}) \mathrm{m} / \mathrm{z} 462$.

2.3. Anti-Inflammatory Activity. Anti-inflammatory activity of piroxicam and prodrugs $3(\mathbf{a}-\mathbf{e})$ was done by carrageenan induced rat paw edema method [12]. Group I served as control and received $5 \mathrm{~mL} / \mathrm{kg}$ of $1 \%$ DMSO as vehicle. Group II received $10 \mathrm{mg} / \mathrm{kg}$ of piroxicam while the remaining test groups III-VII received equivalent doses of synthesized prodrugs $3(\mathbf{a}-\mathbf{e})$. All compounds were administered through oral gavages. After $1 \mathrm{~h}$ of compound administration, $0.1 \mathrm{~mL}$ of $1 \%$ carrageenan solution prepared using normal saline was injected into the subplanter region of the left hind paw and the edema volume was measured before injection $\left(V_{c}\right)$ and at interval of every hour up to $6 \mathrm{~h}$. The percentage inhibition of edema in each test treated group was calculated using the formula

$$
\% \text { Inhibition }=100\left(1-\frac{\Delta V_{t}}{\Delta V_{c}}\right),
$$

where $\Delta V_{c}$ and $\Delta V_{t}$ are arithmetic mean of increase in paw volume in the control and treated groups, respectively.

2.4. Gastroprotective Activity. Synthesized prodrugs were also evaluated for the ulcerogenic potential by the reported method [13]. The animals were orally given $40 \mathrm{mg} / \mathrm{kg}$ body weight of piroxicam and molecular equivalent of test compounds $3(\mathbf{a}-\mathbf{e})$ as suspension in $0.5 \%$ acacia. The control group was administered only $0.5 \%$ acacia. The animals were fasted $24 \mathrm{~h}$ prior to administration of each of control, standard, and test compounds. The animals were sacrificed $6 \mathrm{~h}$ after administration of drug and food and water were available ad libitum. The gastric mucosa was opened, rinsed with $5 \mathrm{~mL}$ saline, and examined by means of magnifier. The stomachs were carefully examined and ulcers were scored according to severity as follows: 0 - normal colored stomach, 0.5-red coloration, 1-spot ulcers, 1.5 - hemorrhagic streaks, and 2-ulcers $>3 \mathrm{~mm}$ but $<5 \mathrm{~mm}$ and 3 -ulcers $>5 \mathrm{~mm}$. The ulcer index was calculated as mean for all animals in the group.

\section{Results and Discussion}

3.1. Chemistry. The designing of prodrugs has given the success to overcome the undesirable properties associated with the parent drug, piroxicam. The novel prodrug derivatives were synthesized and characterized successfully by conjugating piroxicam with various carboxylic acids such as acetic acid, benzoic acid, p-toluic acid, m-toluic acid, and cinnamic acid individually. The reaction was assisted by coupling with DCC, which proves to be an effective catalyst for the conversion of carboxylic acids to esters and amides. It functions by activating the free carboxylic group. Use of DCC is advantageous over other methods like conversion of acid to acid chloride and later on to esters [14]. The synthesized compounds were purified and further characterized for confirmation of their structures. Infrared spectra showed the characteristics peak in the range of 1745$1778 \mathrm{~cm}^{-1}$ for stretching of carbonyl function of esters. The peak for stretching due to carbonyl function of amide group appeared in the range of 1629 to $1685 \mathrm{~cm}^{-1}$. The ${ }^{1} \mathrm{HNMR}$ spectra showed the presence of multiplet in the region of $\delta$ 7.22-8.43 due to aromatic protons. The amide protons appeared as broad singlet in the region of $\delta 9$. These characteristic chemical shifts anticipated the structures of the said compounds. The mass spectra of synthesized compounds showed the parent peak confirming the molecular weight of targeted derivatives.

3.2. Pharmacology. Anti-inflammatory screening of piroxicam and synthesized prodrugs $\mathbf{3}(\mathbf{a}-\mathbf{e})$ is represented in Table 1. It was found from the results that the nature of various substituent used affected the biological activity of the synthesized analogues. The activity data depicts the antiinflammatory potential of synthesized compounds and all of ester analogues were found to be more active than parent piroxicam. This is due to the fact that the acidic promoieties used here are known to possess anti-inflammatory and 
analgesic activity as revealed by previous studies $[9,10]$. All the prodrugs showed increased inhibition of paw edema than piroxicam right from the first hour of dosing. It might be due to the ready cleavage of ester bond as the activity is attributed to piroxicam. It also supports the fact that bulkier promoiety promotes faster release. Compound $\mathbf{3 e}$, a cinnamic acid ester prodrug of piroxicam, was found to have highest anti-inflammatory potential with inhibition of paw edema of $76 \%$ in comparison to $56 \%$ inhibition as shown by piroxicam after $6 \mathrm{~h}$. Consequently, the overall study exposed that acid substituted derivatives are more active anti-inflammatory agents than piroxicam itself.

Determination of ulcer index is indicative of minimized gastrointestinal side effects obtained by modification to prodrug. The synthesized prodrugs $\mathbf{3}(\mathbf{a}-\mathbf{e})$ show very less gastric ulcers than parent drug piroxicam. The data presented in Table 1 indicates that the risk of ulcer induction is reduced by almost 2-4-fold in prodrugs. This might be due to inhibition of direct contact of enolic hydroxyl group of the drug to the gastric mucosa, which is mainly responsible for the damage [15]. These findings suggested the successful masking when coupled with that of promoieties and the ester prodrugs of piroxicam protected the gastric mucosa from injury as evoked.

\section{Conclusions}

The present work aims to increase the therapeutic effectiveness of piroxicam, by masking the enolic hydroxyl group through the acids and converting them to esters. The studies showed that prodrug approach can be successfully applied in attaining the goal of minimized gastrointestinal toxicity with retention of desired anti-inflammatory activity. Thus it gives an opportunity to medicinal chemist to improve the clinical and therapeutic effectiveness of a drug that is suffering from some undesirable properties hindering its clinical usefulness.

\section{Conflict of Interests}

The authors declare that there is no conflict of interests regarding the publication of this paper.

\section{Acknowledgment}

The authors are thankful to Cadila Health Care Ltd., Ahmadabad (India), for providing gift sample of piroxicam.

\section{References}

[1] A. L. Blower and C. P. Armstrong, "Perforated duodenal ulcers," The British Journal of Surgery, vol. 74, no. 8, p. 759, 1987.

[2] S. Pal, P. Bindu, P. K. Dubey, S. Chakraborty, and A. K. Mukherjee, "Synthesis and structure analysis of cyclodehydration product of piroxicam: a metabolite detected in dogs and monkeys," European Journal of Medicinal Chemistry, vol. 44, no. 8, pp. 3368-3371, 2009.

[3] C. N. Aguwa, "Incidence of gastric ulcers by indomethacin and piroxicam in rats," Archives of Toxicology, vol. 56, no. 3, pp. 212$213,1984$.
[4] S. Kawai, F. Kojima, and N. Kusunoki, "Recent advances in nonsteroidal anti-inflammatory drugs," Allergology International, vol. 54, no. 2, pp. 209-215, 2005.

[5] N. M. Nielsen and H. Bundgaard, "Glycolamide esters as biolabile prodrugs of carboxylic acid agents: synthesis, stability, bioconversion, and physicochemical properties," Journal of Pharmaceutical Sciences, vol. 77, no. 4, pp. 285-298, 1988.

[6] T. J. Carty, A. Marfat, F. F. Moore, F. C. Falkner, T. M. Twomey, and A. Weissman, "Ampiroxicam, an anti-inflammatory agent which is a prodrug of piroxicam," Agents and Actions, vol. 39, no. 3-4, pp. 157-165, 1993.

[7] J. Jayaselli, J. M. S. Cheemala, D. P. Geetha Rani, and S. Pal, "Derivatization of enolic $\mathrm{OH}$ of piroxicam: a comparative study on esters and sulfonates," Journal of the Brazilian Chemical Society, vol. 19, no. 3, pp. 509-515, 2008.

[8] M. F. Rafferty and G. Johnson, Morris Plains, N.J., 260/404, 4,689,182, Warner-Lambert Company, 1987.

[9] M. E. Godoy, A. Rotelli, L. Pelzer, and C. E. Tonn, "Antiinflammatory activity of cinnamic acid esters," Molecules, vol. 5, no. 3, pp. 547-548, 2000.

[10] L. P. Zhang and Z. Z. Ji, "Synthesis, antiinflammatory and anticancer activity of cinnamic acids, their derivatives and analogues.," Acta Pharmaceutica Sinica, vol. 27, no. 11, pp. 817823, 1992.

[11] H. Park, R. Kumareswaran, and T. V. RajanBabu, “Tunable phosphinite, phosphite and phosphoramidite ligands for the asymmetric hydrovinylation reactions," Tetrahedron, vol. 61, no. 26, pp. 6352-6367, 2005.

[12] C. A. Winter, E. A. Risley, and G. W. Nuss, "Carrageenininduced edema in hind paw of the rat as an assay for antiiflammatory drugs," Proceedings of the Society for Experimental Biology and Medicine, vol. 111, pp. 544-547, 1962.

[13] V. Cioli, S. Putzolu, V. Rossi, P. Scorza Barcellona, and C. Corradino, "The role of direct tissue contact in the production of gastrointestinal ulcers by anti-inflammatory drugs in rats," Toxicology and Applied Pharmacology, vol. 50, no. 2, pp. 283289, 1979 .

[14] A. Mishra, R. Veerasamy, P. K. Jain, V. K. Dixit, and R. K. Agrawal, "Synthesis, characterization and pharmacological evaluation of amide prodrugs of ketorolac," European Journal of Medicinal Chemistry, vol. 43, no. 11, pp. 2464-2472, 2008.

[15] V. K. Redasani and S. B. Bari, "Synthesis and evaluation of mutual prodrugs of ibuprofen with menthol, thymol and eugenol," European Journal of Medicinal Chemistry, vol. 56, pp. 134-138, 2012. 


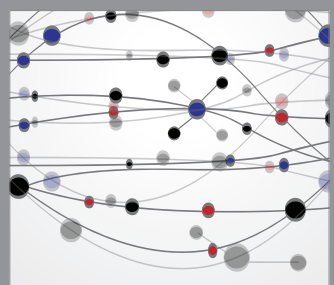

The Scientific World Journal
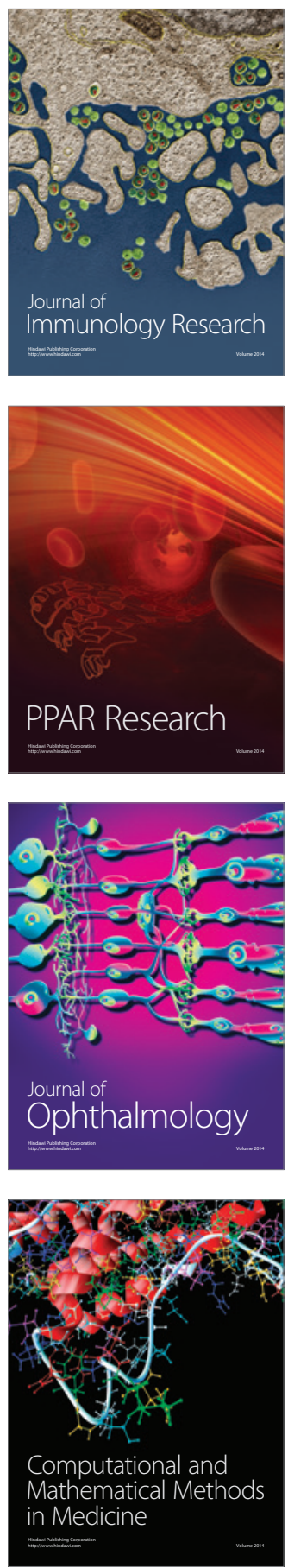

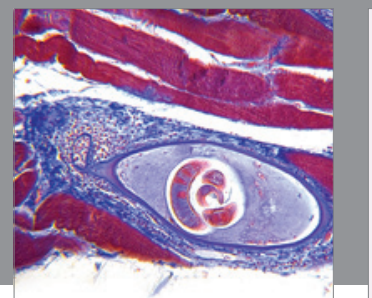

Gastroenterology

Research and Practice
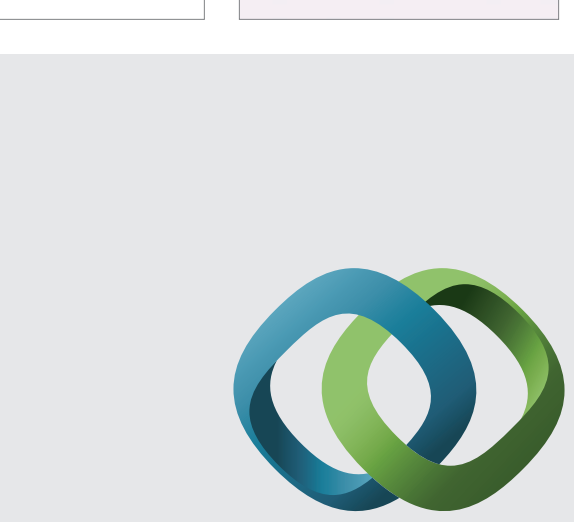

\section{Hindawi}

Submit your manuscripts at

http://www.hindawi.com
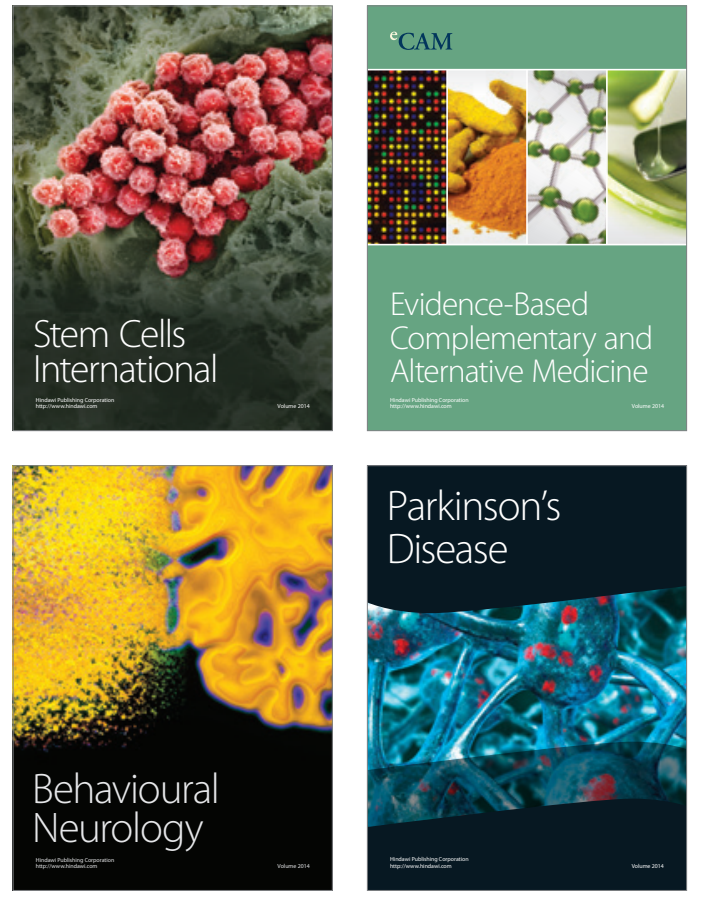
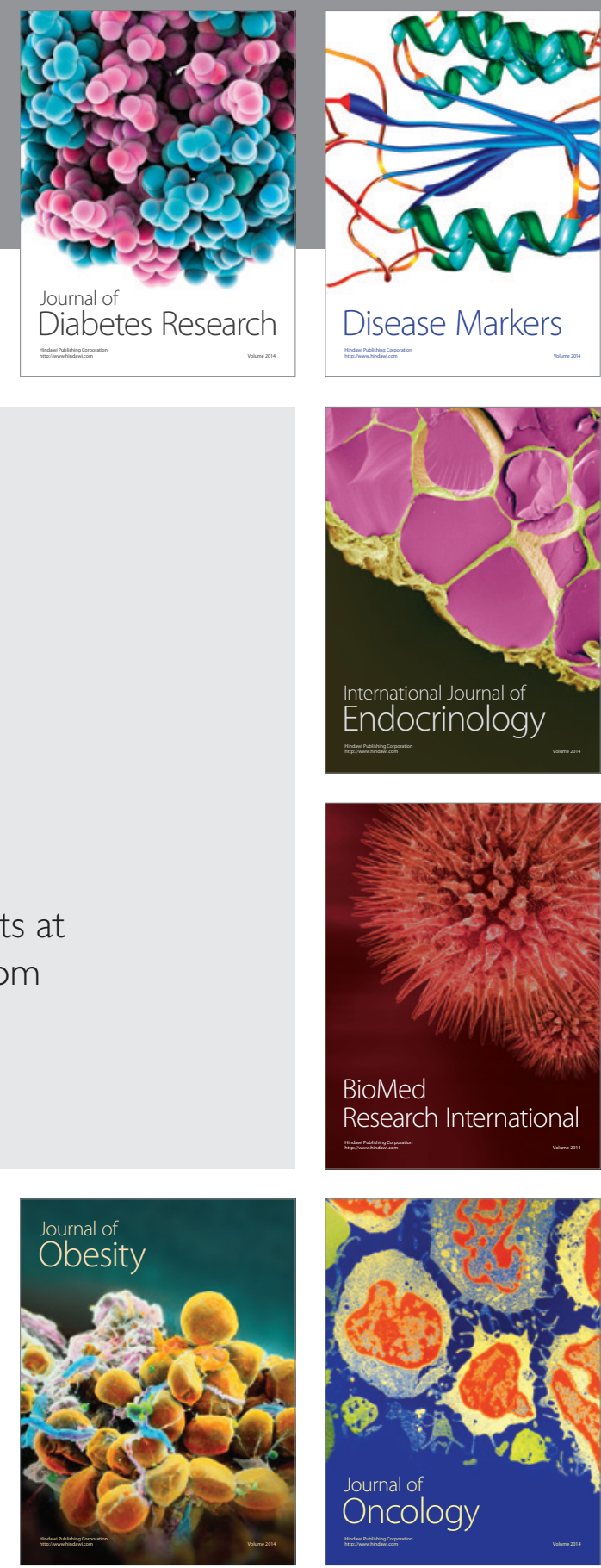

Disease Markers
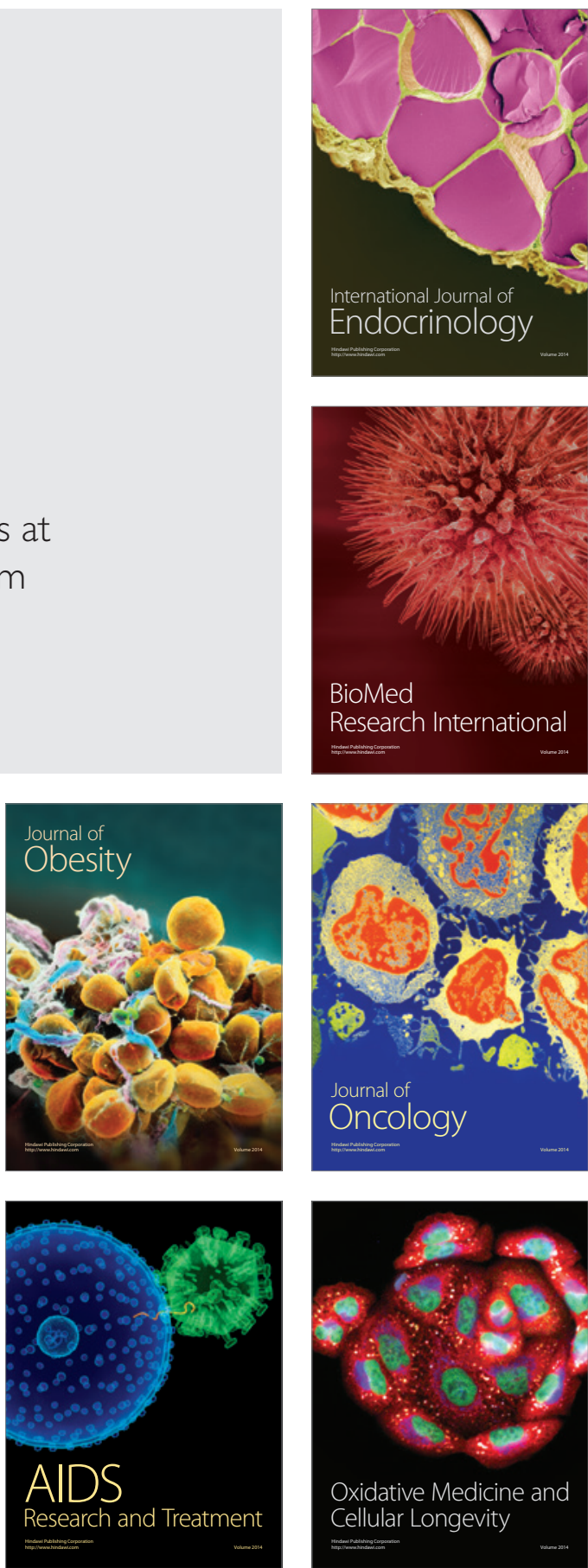